Thematic course: Kinetics and mechanism of acyl transfer reactions. Part 17.

\title{
Quantum-chemical study of mechanisms of sulfonation of benzoic and benzenesulfonic acids hydrazides in the gas phase
}

\author{
(C) Ludmila B. Kochetova, Tatyana P. Kustova, ${ }^{{ }^{+}}$and Alyona A. Kruglyakova \\ Department of Organic and Physical Chemistry. Ivanovo State University. \\ Ermak St., 39. Ivanovo, 153025. Russia.Phone: +7 (84932) 37-37-03.E-mail: kustova_t@mail.ru
}

\begin{abstract}
*Supervising author; ${ }^{+}$Corresponding author Keywords: quantum chemical simulation, reaction mechanism, sulfonylation, benzhydrazide, benzenesulfohydrazide, 3-nitrobenzenesulfonyl chloride.
\end{abstract}

\begin{abstract}
Quantum-chemical simulation of the mechanisms of 3-nitrobenzenesulfonyl chloride interaction with benzhydrazide (RHF/6-31G(d)) and benzenesulfohydrazide (DFT//B3LYP/6-311G(d,p)) in the gas phase was carried out. Three-dimensional potential energy surfaces of these processes are calculated in the coordinates of the angle of attack of the nucleophile and the distance between the reacting molecules. It has been established that in the both cases considered, reactions can proceed in the gas phase along a single route, through a single saddle point corresponding to a single transition state; processes begin as an axial attack of nucleophile, which subsequently proceeds with a decrease in the attack angle as the reagents molecules approach each other. It was shown that the both studied processes proceed in accordance with the bimolecular concerted mechanism of nucleophilic substitution $\mathrm{S}_{\mathrm{N}} 2$, which involves the formation of a single transition state in a reaction pathway and the absence of intermediates on it. Scanning the internal coordinate of benzhydrazide reaction with 3-nitrobenzenesulfonyl chloride made it possible to confirm the reaction route and mechanism of the process pointed out and to clarify the structure of its products and reagents. It was found that the geometric structure of the reaction center in the reactions transition states is medium between the trigonal-bipyramidal and tetragonal-pyramidal, which is due to the change in the nucleophilic attack angle when the reagents molecules approach each other. It was found that in reactions involving hydrazides a "synchronous" transition state is formed in which a new S-N bond is formed simultaneously with the loosening of the old S-Cl bond. The activation energies of the reactions are calculated; they amounted to 173 and $113 \mathrm{~kJ} / \mathrm{mol}$, respectively. The high values obtained are explained by the fact that the simulation was carried out for processes occurring in a gas hase. It was shown that the decrease in the activation energy of the reaction involving benzenesulfohydrazide as compared to the benzhydrazide reaction is due to a decrease in steric hindrances during nucleophilic attack created by the lone electron pair of the benzenesulfohydrazide secondary amino group as compared to the benzhydrazide molecule. The calculated values of charges on the nitrogen atoms of the $-\mathrm{NH}-$ groups in the hydrazides molecules indicate a weakening of the $\alpha$-effect upon the transition from benzenesufohydrazide to benzhydrazide.
\end{abstract}

\section{References}

[1] T.P. Kustova, L.B. Kochetova, and N.V. Kalinina. Reactivity of $\alpha$-alanine in arensulfonylation in aqueous-organic media: kinetic experiment and reaction root simulation. Butlerov Communications. 2011. Vol.27. No.13. P.1-12. ROI: jbc-02/11-27-13-1

[2] N.R. Sokolova, E.V. Nikitina, L.B. Kochetova, N.V. Kalinina, and T.P. Kustova. Kinetics and mechanism of acyl transfer reactions. Part 2. Kinetics of heterocyclic amines arensulfonylation in aqueous 1,4-dioxane. Butlerov Communications. 2012. Vol.29. No.1. P.7-14. ROI: jbc-02/12-29-1-7

[3] L.B. Kochetova, N.V. Kalinina, L.V. Kuritsyn, E.V. Nikitina and T.P. Kustova. The kinetics and mechanism of the acyl transfer. Part 3. Glycine and ammonia reactivity in acyl transfer reactions. Butlerov Communications. 2012. Vol.30. No.6. P.81-88. ROI: jbc-02/12-30-6-81

[4] L.B. Kochetova, M.G. Paikova, N.V.Kalinina, and T.P. Kustova. Kinetics and mechanism of acyl transfer reactions. Part IV. Quantum chemical simulation of the mechanism of benzoyl chloride and benzenesulphonyl chloride interactions with amino compounds of different classes. Butlerov Communications. 2013. Vol.35. No.9. P.1-8. ROI: jbc-02/13-35-9-1 
[5] L.B. Kochetova, N.V. Kalinina, T.P. Kustova, and L.V. Kuritsyn. Kinetics and mechanism of acyl transfer reactions. Part 5.Dipeptides and amino acids reactivity in sulfamide bond formation processes Butlerov Communications. 2013. Vol.36. No.12. P.1-7. ROI: jbc-02/13-35-12-1

[6] L.B. Kochetova, N.V. Kalinina, T.P. Kustova, and L.V. Kuritsyn. Kinetics and mechanism of acyl transfer reactions. Part 6. Quantum chemical interpretation of dipeptides and aminoacids reactivity in processes of acids amides and sulfamides formation. Butlerov Communications. 2013. Vol.36. No.12. P.97-104. ROI: jbc02/13-36-12-97

[7] T.V. Kuritsyn, L.B. Kochetova, N.V. Kalinina, and T.P. Kustova. Kinetics and mechanism of acyl transfer reactions. Part 7. Influence of $\mathrm{pH}$ medium on the reactivity of amines in $\mathrm{N}$-acylation. Butlerov Communications. 2014. Vol.37. No.1. P.33-38. ROI: jbc-02/14-37-1-33

[8] L.B.Kochetova, N.V. Kalinina, L.V. Kuritsyn, and T.P. Kustova. Kinetics and mechanism of acyl transfer reactions. Part 8. Influence of the solvent water-2 propanol composition on the kinetics of alyphatic amines reactions with 4-nitro phenylbenzoate. Butlerov Communications. 2014. Vol.38. No.5. P.39-47. ROI: jbc-02/14-38-5-39

[9] L.B. Kochetova, N.V. Kalinina, L.V.Kuritsyn, and T.P. Kustova. Kinetics and mechanism of acyl transfer reactions. Part 9. Influence of ester structures on kinetics of piperidine and morfoline $N$-acylation in aqueous-organic solvents. Butlerov Communications. 2014. Vol.40. No.11. P.59-66. ROI: jbc-02/1440-11-59

[10] L.B. Kochetova, N.V. Kalinina, Yu.E. Grabchilova, K.A. Simonova, and T.P. Kustova. Kinetics and mechanism of acyl transfer reactions. Part 10.Reactivity of dipeptides and esters of carboxylic acids at their interaction in aqueous dioxane solutions. Butlerov Communications. 2015. Vol.43. No.7. P.1-11. DOI: $10.37952 /$ ROI-jbc-01/15-43-7-1

[11] L.B.Kochetova, N.V. Kalinina, D.S. Soloviyova, O.Yu. Dicina, L.V. Kuritsyn, and T.P. Kustova. Kinetics and mechanism of acyl transfer reactions. Part 11. $L$-Lysine and $L$-ornitine reactivity in reactions with 4-nitrophenyl acetate and picryl benzoate in aqueous 1,4-dioxane solutions. Butlerov Communications. 2016. Vol.45. No.1. P.145-151. DOI: 10.37952/ROI-jbc-01/16-45-1-145

[12] L.B. Kochetova, T.P. Kustova, L.V.Kuritsyn and O.Y. Dicyna. Kinetics and mechanism of acyl transfer reactions. Part 12. Reactivity of aryl amines in amides formation. Butlerov Communications. 2016. Vol.47. No.9. P.95-105. DOI: 10.37952/ROI-jbc-01/16-47-9-95

[13] L.B. Kochetova, T.P. Kustova, D.E. Troitskaya, and Yu.M. Romanova. Kinetics and mechanism of acyl transfer reactions. Part 13. Quantum chemical simulation of mechanisms of the reactions of secondary fatty aromatic amines arensulfonation. Butlerov Communications. 2017. Vol.51. No.9. P.45-56. DOI: 10.37952/ROI-jbc-01/17-51-9-45

[14] L.B. Kochetova, and T.P. Kustova. Kinetics and mechanism of acyl transfer reactions. Part 14. Aminolysis of esters: kinetic experiment and computer simulation of the mechanism. Butlerov Communications. 2018. Vol.53. No.1. P.33-56. DOI: 10.37952/ROI-jbc-01/18-53-1-33

[15] L.B. Kochetova and T.P. Kustova. Kinetics and mechanism of acyl transfer reactions. Part 15. Quantum chemical simulation of mechanisms of reactions of $N$-ethylaniline sulfonation. Butlerov Communications. 2019. Vol.57. No.2. P.19-27. DOI: 10.37952/ROI-jbc-01/19-57-2-19

[16] L.B. Kochetova and T.P. Kustova. Kinetics and mechanism of acyl transfer reactions. Part 16. Quantum chemical simulation of mechanism of $\mathrm{N}$-methylaniline sulfonation in aqueous 1,4-dioxane. Butlerov Communications. 2020. Vol.61. No.1. P.1-8. DOI: 10.37952/ROI-jbc-01/20-61-1-1

[17] Kinetika reaktsiy atsyl'nogo perenosa. Kuristyn L.V. [and etc.]; ed. by L.V. Kuristyn. Ivanovo: Ivan. gos. univ. 2006. 260p. (russian)

[18] Granovsky Alex A., Firefly version 7.1.G. www http://classic.chem.msu.su /gran/firefly/index.html.

[19] T.P. Kustova, A.A. Kruglyakova, L.B. Kochetova, M.S. Gruzdev. Optimizatsia usloviy sinteza produktov sulfonilirovaniya gidrazidov benzoinoy i benzolsul'fonovoy kislot. Zhurnal prikladnoy khimii. 2016. Vol.89. No4. P.495-504. (russian)

[20] L.B. Kochetova, T.P. Kustova, N.V. Kalinina, N.R. Ishkulova, V.V. Lutsuk. Kvantovo-khimicheskoe modelirovanie mekhanizma vzaimodeistviya arensulfonylkhloridov s $\alpha$-aminokislotami. Teoreticheskaya i eksperimentalnaya khimiya. 2011. Vol.47. No.1. P.56-60. (russian)

[21] C.H. DePuy, E.W. Della, J. Filley, J.J. Grabowski, V.M. Bierbaum. Absence of an alpha-effect in the gasphase nucleophilic reactions of hydroperoxide ion. Journal of the American chemical society. 1983.

Vol.105. No.8. P.2481-2482. 